\title{
DEMOCRACIA E DIREITOS HUMANOS: A PARTICIPAÇÃO SOCIAL DAS MINORIAS
}

\section{DEMOCRACY AND HUMAN RIGHTS: SOCIAL PARTICIPATION OF MINORITIES}

\begin{abstract}
CAMILA Bibiana Freitas BaRALDI
Doutora em Relações Internacionais (IRI/USP), mestre em Direito (PPGD/UFSC) e bacharel em Direito (UFSM; Università Degli Studi di Trento - Itália e Université de Paris XIII - França). Atualmente é Coordenadora-Adjunta de Políticas para Migrantes da Secretaria Municipal de Direitos Humanos e Cidadania de São Paulo. Professora de Direito Internacional da Faculdade Santa Marcelina - São Paulo baraldicamila@gmail.com

Pedro Pulzatto Peruzzo Mestre e doutorando em Direito pela Universidade de São Paulo-USP. Advogado com atuação junto a movimentos sociais. Atualmente exerce também o cargo de assessor técnico da Coordenação de Educação em Direitos Humanos da Secretaria Municipal de Direitos Humanos e Cidadania de São Paulo, bem como de Diretor da Comissão de Direitos Humanos da $116^{\circ}$ Subseção da Ordem dos Advogados do Brasil. É professor de Direito Constitucional do Centro Universitário Estácio Radial de São Paulo.
\end{abstract} peruzzopp@hotmail.com

\section{RESUMO}

A Constituição de 1988 prevê que todo o poder emana do povo, que o exerce por meio de representantes eleitos ou diretamente. Do mesmo modo, consagra como objetivo da República Federativa do Brasil a promoção do bem todos, sem preconceito de origem, raça, sexo, cor, idade e quaisquer outras formas de discriminação. Apesar das previsões constitucionais, a participação política das minorias ainda não é uma realidade estrutural da política brasileira. Apesar disso, existem experiências importantes em curso com vistas à concretização da democracia participativa e o registro de avanços importantes no que diz respeito à ampliação das vias de participação popular na formulação de leis e de políticas públicas que afetem as minorias é uma forma de avaliar e seguir avançando no enraizamento social da democracia participativa no Brasil. Neste artigo pretendemos justificar a importância e a possibilidade da participação social das minorias nas tomadas de decisão sobre assuntos públicos do país e registrar experiências positivas que têm envolvido grupos minoritários nas tomadas de decisão.

Palavras-chave: Democracia participativa; Direitos Humanos; Minorias; Direito à diferença; Interculturalidade.

\begin{abstract}
The 1988's Constitution provides that all power emanates from the people, who exercise it through elected representatives or directly. Similarly, enshrines the objective of the Federative Republic of Brazil to promote the general welfare without prejudice of origin, race, sex, color, age and any other forms of discrimination. Despite the constitutional provisions, the political participation of minorities is still not a structural reality of Brazilian politics. Nevertheless, there are important ongoing experiences to achieving participatory democracy. Registering these important advances with regard to the expansion of popular participation in the formulation of laws and public policies that affect minorities is a way to evaluate and move forward in the social roots of participatory democracy in Brazil. This article aims to explain the importance and the possibility of social participation of minorities in decision-making on public affairs of Brazil and register positive experiences that have involved minority groups in decision making.
\end{abstract}

Keywords: Participatory democracy; Human rights; minorities; Right to be different; Interculturalism. 


\section{SUMÁRIO}

INTRODUÇAO; 1 DIREITOS HUMANOS E INTERCULTURALIDADE; 2 O PRECONCEITO E A DISCRIMINAÇÃO EM RELAÇÃO ÀS MINORIAS; 3 DEMOCRACIA E PARTICIPAÇÃO SOCIAL; CONCLUSÃO; REFERÊNCIAS.

\section{INTRODUÇÃO}

O primeiro artigo da Constituição de 1988 diz que a República Federativa do Brasil constitui-se em estado democrático de direito e tem como fundamentos a soberania, a cidadania, a dignidade da pessoa humana, os valores sociais do trabalho e da livre iniciativa e o pluralismo político, consignando ainda, em seu parágrafo único, que todo o poder emana do povo, que o exerce por meio de representantes eleitos ou diretamente.

Além disso, ao fixar como objetivo da República Federativa do Brasil a construção de uma sociedade livre, justa e solidária (artigo $3^{\circ}$, inciso I) e a promoção do bem todos, sem preconceito de origem, raça, sexo, cor, idade e quaisquer outras formas de discriminação (artigo $3^{\circ}$, inciso IV), a Constituição de 1988 avança sobre a ideia reducionista e equivocada que diz ser a democracia o simples resultado da vontade da maioria. Consagra assim uma concepção democrática que se preocupa com o bem de todos, sem exclusão de ninguém e institui uma base hermenêutica para uma leitura mais participativa e aberta de todo o ordenamento jurídico brasileiro, compreendendo o povo (demos) como um conjunto plural de titulares do poder (kratos).

Nesse sentido, o desenvolvimento das ideias que serão apresentadas neste trabalho partirá dessa concepção de democracia que não olvida as minorias, ou seja, levará em conta a ideia de democracia que, sim, busca obter legitimidade no consenso da maioria, mas que também, e principalmente, exige que esse consenso seja resultado de um momento participativo anterior. Neste, todos, inclusive as minorias, devem ter tido a oportunidade de participar dos debates, de manifestar suas opiniões, de sugerir alternativas e de se apresentar enquanto grupo divergente e, por isso mesmo, enquanto grupo que faz viva a diversidade protegida pela Constituição.

Neste trabalho trataremos da relevância democrática da participação social das minorias com atenção especial a alguns exemplos e foros em que essa participação tem se mostrado efetiva. Não 
temos a pretensão de analisar problemas específicos relacionados às experiências participativas de grupos individualizados, mas sim de considerar avanços em grupos que historicamente foram excluídos das tomadas de decisão sobre assuntos públicos que lhes dizem respeito.

A preocupação com a participação das minorias nas tomadas de decisão nos assuntos públicos tem a ver com a preocupação da legitimidade do Direito e das políticas públicas, cujo caráter democrático se fortalece na medida em que a participação social se enraíza na sociedade à qual se destinam. A previsão constitucional de instrumentos de participação social pode corresponder assim à forma plural da sociedade brasileira ${ }^{1}$. A democracia brasileira é uma experiência ainda recente e apesar de ter sido construída sobre estruturas marcadas por uma tradição colonial e impregnadas por manchas de ditaduras civis-militares, podemos registrar avanços importantes no que diz respeito à ampliação das vias de participação social das minorias. Neste artigo a participação social das minorias será abordada com o objetivo de registrar avanços como a consulta prévia aos povos tradicionais e a inclusão de imigrantes nos Conselhos Participativos das Subprefeituras da cidade de São Paulo, de forma a avaliar e seguir avançando no enraizamento social da democracia participativa no Brasil.

\section{DIREITOS HUMANOS E INTERCULTURALIDADE}

A definição do que entendemos por "direitos humanos" é muito importante, pois há algum tempo a mídia tem contribuído consideravelmente para desvirtuar o seu sentido, ignorando a importância dessa semântica para a compreensão das injustiças sociais arraigadas na estrutura da sociedade brasileira. É o fundamento dos direitos humanos que permite pensar o Direito, normalmente rígido e etnocentrado, de forma mais aberta para as diferenças.

Quando falamos em direitos humanos, portanto, falamos em um fundamento, em uma semântica, que exige o recurso a outros direitos diretamente dependentes e complementares do direito violado. Em outros termos, considerando a interdependência e complementaridade dos direitos humanos, é fundamental a compreensão de que em algumas situações um ser humano precisará ter garantido um conjunto amplo de direitos para que um direito humano seja assegurado

\footnotetext{
1 A esse respeito, Joaquim José Gomes Canotilho diz do Direito Constitucional: (...) o direito constitucional é um sistema aberto de normas e princípios que, através de processos judiciais, procedimentos legislativos e administrativos, iniciativas dos cidadãos, passa de uma law in book para uma law in action, para uma living constitution. (Cf. CANOTILHO, J.J. G. Direito Constitucional. 5. ed. Coimbra: Almedina, 1991. p.175/176.)
} 
de maneira integral. É o caso, por exemplo, do direito humano à participação social, que exige medidas de educação inclusiva, de combate à discriminação e ao preconceito, entre outras, para que seu exercício seja efetivo. Em relação às minorias, vale recordar a forma como Boaventura de Souza Santos trabalha a questão: Temos o direito a ser iguais quando a diferença nos inferioriza; temos $o$ direito a ser diferentes quando a igualdade nos descaracteriza. ${ }^{2}$

O papel dos direitos humanos, portanto, em relação às minorias, é exatamente assegurar o protagonismo de grupos historicamente alijados dos processos de tomadas de decisão sobre assuntos públicos. Exatamente por isso, a reflexão sobre a participação social das minorias se fortalece quando empreendida a partir do discurso dos direitos humanos fundamentais, pois como afirmou Vieira de Andrade:

$\mathrm{Na}$ realidade, e em geral, verifica-se que, embora a ideia dos direitos fundamentais tenha surgido para defesa dos cidadãos contra o Estado, pressupõe (e, bem vistas as coisas, sempre pressupôs) a existência de um poder estadual que os assegure. Mais concretamente, a ideia constitucional dos direitos fundamentais afirmou-se para proteção dos cidadãos, não só contra o Executivo monárquico (para isso bastaria a legalidade administrativa), mas contra as próprias maiorias parlamentares, que deveriam respeitar valores tão importantes como o estatuto fundamental dos indivíduos na sociedade política (...). ${ }^{3}$

A complexidade das situações em que grupos e indivíduos social e culturalmente diferenciados compartilham e convivem num mesmo espaço político e geográfico, no entanto, sempre emerge nessa discussão. Novamente, a referência aos direitos humanos assegura o direito de todos compartilharem de maneira não violenta o mesmo espaço. A isto soma-se, ainda, a compreensão do que se deve entender por interculturalidade, como veremos, a qual é fundamental para afastar algumas premissas preconceituosas que normalmente estão presentes nas reflexões sobre esse tema.

\footnotetext{
${ }^{2}$ SANTOS, B. S. A gramática do tempo: para uma nova cultura política. 3 ed. São Paulo: Cortez, 2010. p. 462.

${ }^{3} \mathrm{Na}$ realidade, e em geral, verifica-se que, embora a ideia dos direitos fundamentais tenha surgido para defesa dos cidadãos contra o Estado, pressupõe (e, bem vistas as coisas, sempre pressupôs) a existência de um poder estadual que os assegure. Mais concretamente, a ideia constitucional dos direitos fundamentais afirmou-se para proteção dos cidadãos, não só contra o Executivo monárquico (para isso bastaria a legalidade administrativa), mas contra as próprias maiorias parlamentares, que deveriam respeitar valores tão importantes como o estatuto fundamental dos indivíduos na sociedade política (...). (Cf. ANDRADE, J. C. V. Os direitos fundamentais na Constituição de 1976. 2. ed. Coimbra: Almedina, 2001. p.199.)
} 
As teses universalistas tradicionais desconsideram a existência de diferenças culturais, econômicas, políticas e sociais e as teses relativistas desconsideram o fato de existirem vários grupos convivendo num mesmo espaço, bem como negam a possibilidade de entendimentos entre interlocutores social e culturalmente diferenciados. Por isso mesmo, nenhuma dessas abordagens se mostrou suficiente para a construção de um espaço político em que os diferentes e as minorias pudessem negociar seus interesses de forma autônoma e independente. A tese universalista tradicional desconsidera as estruturas hegemônicas existentes, que mantém, na prática, as minorias em condição de inferioridade política e econômica, enquanto a tese relativista desconsidera a necessidade do entendimento para a construção de espaços democráticos de convivência.

Joaquín Herrera Flores diz sobre essa questão: $O$ que negamos é considerar o universal como um ponto de partida ou um campo de desencontros. Ao universal há que se chegar - universalismo de chegada ou de confluência - depois (não antes) de um processo conflitivo, discursivo de diálogo (...). ${ }^{4}$ Não existe, portanto, um universal a priori, mas a ideia de um universal em que as diferenças possam conviver de maneira respeitosa, exigindo o diálogo, as trocas, os choques e conflitos argumentativos, e é nesse processo de experiência sensível com o "outro" que os entendimentos e os acordos podem ser formulados concretamente. A distância, as cercas, as fronteiras e outras barreiras impedem o diálogo e, por tudo o que sustentamos até aqui, o diálogo nos parece imprescindível para a construção de uma sociedade livre, justa e solidária, como consta do artigo $3^{\circ}$, inciso I, Constituição de 1988.

Nesta linha, considerando que o compartilhamento de espaços comuns exige processos permanentes de diálogo e de respeito às diferenças, é necessário avançar em relação à simples ideia de tolerância e é nesse sentido que definimos a interculturalidade. A esse respeito vale ainda a referência ao conceito de patriotismo constitucional. Maria Eugênia Bunchaft ${ }^{5}$, analisando a aplicação do termo na obra de Jürgen Habermas, explica-o como sendo uma nova maneira de fornecer um modelo de identificação política capaz de superar o nacionalismo,

\footnotetext{
4 FLORES, Joaquin Herrera. Direitos Humanos, Interculturalidade e Racionalidade de Resistência. Sequência (UFSC), vol. 23, n. 44. 2002. ISSNe 2177-7055. p. 09 a 29.

5 BUNCHAFT, Maria Eugenia. O patriotismo constitucional na perspectiva de Jürgen Habermas: a reconstrução da ideia de nação na filosofia política contemporânea. Rio de Janeiro: Lumen Júris, 2010, p. 42.
} 
concebendo a identidade nacional alemã de forma diversa da compreensão neohistoricista alemã. ${ }^{6}$

Desde já é importante registrar que inúmeros autores se utilizam de termos como interculturalidade ou multiculturalismo sem a preocupação de qualquer alinhamento conceitual mais minucioso. Da mesma forma que abordamos a idéia de “direitos humanos”, buscamos apenas esclarecer o que entendemos por interculturalidade, sem a pretensão de solidificar um conceito teórico para o termo. Para iniciar esse esclarecimento, vale referência ao que Enrique Dussel chamou de "multiculturalismo altruísta”.

\begin{abstract}
A esas culturas que no son ni "metropolitanas" ni "primitivas", se las va destruyendo por medio de la propaganda, de la venta de mercancías, productos materiales que son siempre culturales (como bebidas, comidas, vestidos, vehículos, etc.), aunque por otro lado se pretende salvar dichas culturas valorando aisladamente elementos folclóricos o momentos culturales secundarios. Una trasnacional de la alimentación puede subsumir entre sus menús un plato propio de una cultura culinaria (como el "Taco Bell”). Esto pasa por "respeto" a las otras culturas.
\end{abstract}

Este tipo de multiculturalismo altruista queda claramente formulado en el "overlapping consensus" de un John Rawls, que exige la aceptación de ciertos principios procedimentales (que son inadvertidamente profundamente culturales, occidentales) que deben ser aceptados por todos los miembros de una comunidad política, y permitiendo al mismo tiempo la diversidad valorativa cultural (o religiosa). Políticamente esto supondría en los que establecen el diálogo aceptar un Estado liberal multicultural, no advirtiendo que la estructura misma de ese Estado multicultural tal como se institucionaliza en el presente es la expresión de la cultura occidental y restringe la posibilidad de sobrevivencia de todas las demás culturas. Subrepticiamente se ha impuesto una estructura cultural en nombre de elementos puramente formales de la convivencia (que han sido expresión del desarrollo de una cultura determinada). Además, no se tiene clara conciencia que la estructura económica de fondo es el capitalismo trasnacional, que funda ese tipo de Estado liberal, y que ha limado en las culturas "incorporadas", gracias al indicado

\footnotetext{
${ }^{6}$ Vale referência também a outro texto de Maria Eugenia Bunchaft em que a autora anota: Em sociedades multiculturais, uma cultura política que é delineada a partir da adesão a princípios de direitos humanos, pode assegurar um grau de integração social capaz de transcender os vínculos de língua, cultura e etnia. Assim, em relação à União Europeia, Habermas sublinha que sua identidade política deve decorrer não de uma realidade culturalmente homogênea, mas do compromisso dos cidadãos europeus com os princípios de direitos humanos, gerando uma nova forma de identidade política universalista. Sobre as críticas ao patritismo constitucional, anota ainda: Entretanto, autores como Cronin, Lacroix e Shabani enfrentam as críticas formuladas por meio de uma reinterpretação da teoria do patriotismo constitucional, contraargumentando que o patriotismo constitucional apenas procura relativizar o nacionalismo, negando as interpretações xenófobas de identidade nacional, mas pode se compatibilizar com o respeito às identidades nacionais distintivas. (Cf. BUNCHAFT, M. E. Algumas críticas à ideia de patriotismo constitucional. Pensar, v. 16, n. 1, p. 224-245, Fortaleza, jan./jun. 2011).
} 

anticapitalistas de esas culturas) diferencias anti-occidentales inaceptables. ${ }^{7}$

Dessa análise de Dussel destacamos alguns pontos: 1- a aceitação da cultura menos expressiva apenas como consumidora; 2- a valorização isolada de elementos culturais secundários; 3 - a aceitação/imposição de princípios procedimentais dialógicos ocidentais (etnocêntricos); 4- a estrutura do Estado multicultural como expressão da cultura ocidental; 5- a noção de incorporação da cultura menos expressiva.

Como estamos falando de interculturalidade e diálogo intercultural, merece atenção também a idéia da tolerância de diferenças “aceitáveis”. Essa concepção é problemática, pois a cultura não é um objeto compartimentado, plenamente dimensionado, que nos apropriamos quando e como queremos. Não há como tolerar apenas metade de um grupo culturalmente diferenciado (essa prática e aquela outra), pois cada prática cultural tem uma referência tópica, reflexiva, que vai do coletivo ao indivíduo e vice-versa. Nessa linha, Bauman sugere uma discussão que parece relevante para as nossas reflexões, qual seja a necessidade de se compreender que não existe mais a possibilidade de pensarmos, hoje, em culturas homogêneas, como fatos emoldurados ou involucrados por uma ideia de pureza.

Há uma intenção ideológica por trás de cada visão de "cultura homogênea" (...). Tal ideologia raramente foi ressaltada, quanto mais questionada em condições radicalmente diversas das nossas - quando refletia a prática moderna da homogeneização patrocinada pelo poder. Essa ideologia estava á vontade no mundo da construção nacional, das cruzadas culturais, da implantação de padrões uniformes sobre a variedade de estilos de vida, de assimilação forçada e de busca de harmonia cultural. Desde então, porém, o mundo mudou o suficiente para despojar essa ideologia de sua influência na prática política e assim solapar sua reivindicação sobre a realidade. ${ }^{8}$

Essa compreensão exige a apreensão da dimensão dinâmica dos grupos culturais e do inevitável contato entre diversos grupos. Não existe mais espaço para polarizações e isolamentos, pois as polarizações demandam tolerância, e tolerar nos parece pouco. Nesse sentido, a ideia de multiculturalismo que Bauman utilizou para trabalhar a possibilidade de "convivência num mundo das diferenças" apresenta características semelhantes à definição de “muticulturalismo altruísta” de

\footnotetext{
${ }^{7}$ DUSSEL, E. Transmodernidad e interculturalidad -Interpretación desde la Filosofía de la Liberación. In: FORNET-BETANCOURT, R. Crítica Intercultural de la Filosofía Latinoamericana Actual. Madrid, pp. 123160, 2004.

${ }^{8}$ Id.
} 
Dussel. Enquanto Dussel fala da aceitação do outro grupo culturalmente diferenciado apenas na condição de consumidor e da valorização de elementos culturais secundários, Bauman fala de um contato (coexistência tolerante) mediado pelas diferenças aceitáveis. Essas características dizem muito sobre a concepção de tolerância, que carrega consigo não uma relação simétrica de respeito (típica da convivência na alteridade), mas uma relação pautada no cinismo e imposta pela fatalidade da coexistência.

O grupo hegemônico apenas tolera o grupo culturalmente diferenciado, quando o faz, e desde que este grupo consuma o seu excedente e mantenha as suas práticas "estranhas" no âmbito privado de seus redutos concedidos (pelo primeiro grupo). Em troca, ou melhor, como manifestação maculada de respeito, o grupo hegemônico permite que se fale do grupo minoritário em alguns espaços, desde que essa "divulgação do outro" não represente nenhuma ameaça à hierarquia que permanece existindo.

Assim sendo, o primeiro passo para o enraizamento de práticas democráticas participativas como uma forma de garantia e promoção de direitos humanos de minorias em contextos plurais é compreender a importância da interculturalidade, assim entendida a situação em que a coexistência tolerante vai ceder espaço para a convivência respeitosa. Para isso, são imprescindíveis as políticas públicas de combate ao preconceito e à discriminação, bem como as políticas de educação que não apenas permita o respeito pelas diferenças, mas que emancipe as minorias para lutar e promover autonomamente o direito às diferenças.

\section{O PRECONCEITO E A DISCRIMINAÇÃO EM RELAÇÃO ÀS MINORIAS}

O preconceito que emerge da forma como os grupos hegemônicos tratam as minorias é um problema que merece ser evidenciado, pois se o preconceito, o racismo, a xenofobia e outras formas de violência permanecerem arraigadas na sociedade civil e nas estruturas do Estado brasileiro, impossível será avançar no enraizamento de experiências democráticas com a participação social das minorias.

Ao lado dos negros mortos indiscriminada e vergonhosamente pelos braços armados do Estado brasileiro todos os dias nas periferias, imigrantes, indígenas e outros grupos minoritários também têm sido alvo de ataques preconceituosos e discriminatórios não apenas por parte da população, mas especialmente por parte de servidores públicos que ocupam cargos eletivos no Legislativo e no 
Executivo e também pelas polícias nas fronteiras e nas áreas de conflitos fundiários. A fala do Ministro do Interior Maurício Rangel Reis (governo de Ernesto Geisel), em janeiro de 1976, esclarece e resume o que estamos afirmando: “Os índios não podem impedir a passagem do progresso (...) dentro de 10 a 20 anos não haverá mais índios no Brasil." "Mais recentemente, o deputado federal Luís Carlos Heinze (PP-RS), ao se referir ao Governo Federal em 2014, disse: “É ali que estão aninhados quilombolas, índios, gays, lésbicas. Tudo o que não presta ali está aninhado. ${ }^{10 "}$ Ainda, em setembro de 2015 o deputado Jair Bolsonaro disse sobre os refugiados: “A escória do mundo está chegando ao Brasil."

A compreensão de que existem questões comuns a serem enfrentadas pelos diversos grupos minoritários é um salto importante para o enraizamento de práticas democráticas participativas, pois os novos movimentos sociais, que têm trabalhado e atuado na luta por direitos desde a base, não exigem mais, pela própria configuração das relações, uma análise isolada, compartimentada. A respeito dessa questão é muito esclarecedora a análise de Evelina Dagnino, que ao analisar os movimentos sociais emergentes na década de 90 na América Latina propõe a ideia de uma cidadania “de baixo para cima".

\begin{abstract}
Afirmar a cidadania como estratégia significa enfatizar o seu caráter de construção histórica, definida portanto por interesses concretos e práticas concretas de luta e pela sua contínua transformação. Significa dizer que não há uma essência única imanente ao conceito de cidadania, que o seu conteúdo e seu significado não são universais, não estão definidos e delimitados previamente, mas respondem à dinâmica dos conflitos reais, tais como vividos pela sociedade num determinado momento histórico. Esse conteúdo e significado, portanto, serão sempre definidos pela luta política.
\end{abstract}

Uma das conseqüências dessa perspectiva é a necessidade de distinguir a nova cidadania dos anos 90 da visão liberal que, tendo gerado esse termo nos fins do século XVIII como uma resposta do Estado às reivindicações da sociedade, acabou por essencializar a noção de cidadania. Essa "essência", de cunho liberal, continua vigente até hoje, lutando para permanecer como tal e certamente desempenhando funções bastante diferentes daquelas que caracterizaram a sua origem. ${ }^{11}$

\footnotetext{
${ }^{9}$ COMISSÃO NACIONAL DA VERDADE. Relatório Final. Texto 5 - Violações de direitos humanos dos povos indígenas. p. 203-264. Brasília, 2014.

${ }^{10} \mathrm{Cf}$. Publicação da Articulação dos Povos Indígenas do Brasil (APIB):

$<$ https: / / mobilizacaonacionalindigena.wordpress.com/2014/02/12/deputado-ruralista-diz-quequilombolas-indios-e-homossexuais-sao-tudo-o-que-nao-presta-e-defende-que-fazendeiros-usem-armas/>. Acesso em 02 de agosto de 2015.

${ }^{11}$ DAGNINO, E. Os movimentos sociais e a emergência de uma nova noção de cidadania. In. DAGNINO, E (org.), Anos 90 - Política e sociedade no Brasil, Ed. Brasiliense, 1994. p. 103-115.
} 
Após afirmar que essa distinção é tanto política como retórica, Evelina Dagnino apresenta alguns fatores distintivos entre essas concepções de cidadania.

Um primeiro item se refere à própria noção de direitos. Considero que a nova cidadania trabalha com uma redefinição da idéia de direitos, cujo ponto de partida é a concepção de um direito a ter direitos. Essa concepção não se limita portanto a conquistas legais ou ao acesso a direitos previamente definidos, ou à implementação efetiva de direitos abstratos e formais, e inclui fortemente a invenção/criação de novos direitos, que emergem de lutas específicas e da sua prática concreta. A disputa histórica é aqui também pela fixação do significado de direito e pela afirmação de algo enquanto um direito.

Um segundo ponto, que retoma o direito a ter direitos, é que a nova cidadania, ao contrário da concepção liberal, não se vincula a uma estratégia das classes dominantes e do Estado para a incorporação política progressiva dos setores excluídos, com vistas a uma maior integração social, ou como condição jurídica e política indispensável à instalação do capitalismo. A nova cidadania requer (e até é pensada como sendo esse processo) a constituição de sujeitos sociais ativos, definindo o que eles consideram ser os seus direitos e lutando pelo seu reconhecimento. Nesse sentido, ela é uma estratégia dos não cidadãos, dos excluídos, uma cidadania "de baixo para cima". ${ }^{12}$

A igualdade de direitos em relação aos nacionais, ou dito "membros da sociedade nacional", inclui todos os migrantes e também os indígenas e isso está inscrito nos documentos legais brasileiros, da Constituição e se reflete até as políticas públicas em curso em alguns municípios, para não falar da igualdade de direitos entre todos os seres humanos inscrita em diversos Tratados internacionais. Apesar disso, ultimamente temos assistido, lido e ouvido muitas opiniões e reportagens preconceituosas a respeito das migrações de estrangeiros para o Brasil e também sobre a situação deplorável de alguns grupos indígenas, especialmente no Mato Grosso do Sul e no sul da Bahia. 0 preconceito da população acirrado pelo papel irresponsável de alguns veículos de comunicação tem dificultado o enraizamento de práticas democráticas participativas, por exemplo, de imigrantes e indígenas.

Apesar de o movimento migratório para o Brasil ser significativo há pelo menos três décadas, apenas recentemente o tema tem ocupado de forma mais marcante os foros de discussão, em

\footnotetext{
${ }^{12} / d$.
} 
especial as redes sociais ${ }^{13}$. Apesar das inúmeras abordagens, o fato que mais espanta no discurso da população em geral é a desconexão entre as migrações do passado (portugueses, alemães, italianos, japoneses, libaneses, entre outros), intensas no fim do século XIX e início do século XX, e as migrações de sul-americanos, haitianos e africanos que tem ocorrido nas últimas décadas para o Brasil.

A desconexão impressiona não somente pelo desconhecimento histórico, mas pela ausência de reflexão e coerência que revelam as manifestações preconceituosas. 0 próprio processo de imigração de europeus entre os séculos XIX e XX reproduziu a lógica racista que está presente desde a formação do Brasil. Debates sobre o imigrante ideal (aptidão para o trabalho na agricultura e potencial de assimilação eram os requisitos inicialmente pretendidos, recaindo a escolha sobre as nacionalidades europeias) e normas constitucionais que estabeleciam o objetivo de europeização/branqueamento da população nortearam este processo. ${ }^{14}$

Hoje a situação não é diferente. O racismo revestido de seletividade da migração pode se revelar nas regras estabelecidas para a entrada de imigrantes, mas sobretudo, revela-se no quotidiano de imigrantes de pele negra e traços indígenas no Brasil. A xenofobia, por sua vez, também começa a mostrar-se, e funciona como um instrumento de descarte daqueles que os nacionais consideram não servirem, ou seja, vemos aqui uma articulação de diferentes formas de preconceito e exclusão. Nesse sentido, acrescentamos ainda a crítica às tentativas de hierarquizar a legitimidade das diferentes situações de migração: refugiados, migrantes, etc.

O mesmo podemos dizer em relação aos povos indígenas e, a esse respeito, também podemos concluir que a categoria "índio" é uma categoria colonial, inventada, reinventada e aplicada arbitrariamente pelo colonizador e pelos seus sucessores modernos, por equívoco no início e voluntariamente nos anos que se seguiram à chegada dos portugueses. O termo “índio" não representa nem de longe a multiplicidade e a pluralidade das centenas de povos que viviam e que vivem no Brasil e, por isso mesmo, não é suficiente para servir de critério nem para a identificação e nem para a garantia de direitos aos Tupinambá, aos Xavante, aos Wajãpi, aos Terena, aos Macuxi, aos Yanomami, aos Munduruku e todos os outros povos. Como afirmou Vivian Urquidi et. alii., (...) “índio

\footnotetext{
${ }^{13}$ Cf. Imigração + preconceito e discriminação = crime disponível em <http://justificando.com/2015/06/30/imigracao-preconceito-e-discriminacao-=-crime/>, acesso em 26 de setembro de 2015.

${ }_{14}$ Para aprofundar o tema: SEYFERTH, Giralda. As identidades dos imigrantes e o melting pot nacional. Horizontes Antropológicos, Porto Alegre, ano 6, n. 14, 2000; SCHWARCZ, Lilia Moritz. 0 espetáculo das raças: cientistas, instituições e questão racial no Brasil, 1870 - 1930. São Paulo: Companhia das Letras, 1993.
} 
é uma generalização que se inicia desde o primeiro contato do colonizador com os povos conquistados, e que unifica e simplifica a diversidade dos povos indígenas. "15

O preconceito, a discriminação e a declarada empreitada para consumar o genocídio contra os povos indígenas e para "branquear" a dita "sociedade brasileira" tem início com a chegada do colonizador, recrudesce com a ditadura civil-militar brasileira (que produziu o Estatuto do Índio ${ }^{16}$ e 0 Estatuto do Estrangeiro ${ }^{17}$ ) e, apesar do significativo avanço que representa a Constituição de 1988, essas práticas permanecem até hoje arraigadas na sociedade e no Estado brasileiro.

Não são poucos os vídeos de celular que têm circulado no whatsapp, as postagens no facebook contra imigrantes e indígenas, com registros de agressões verbais e ameaças de morte. Apesar disso, pouquíssimas vezes temos notícia de providências contra essas práticas xenófobas por parte das instituições competentes para apurar a prática de crimes dessa natureza (Ministério Público, Polícias, etc.). Não é demais lembrar que o crime de racismo é imprescritível e inafiançável, nos termos do artigo $5^{\circ}$, inciso XLII, da Constituição Federal. Além disso, a Lei 7.716/89 trata dos crimes resultantes de discriminação ou preconceito de raça, cor, etnia, religião ou procedência nacional, prevendo vários tipos penais, com diversas condutas como impedir o acesso a locais públicos ou privados, negar ou obstar emprego etc., sendo o tipo penal mais complexo o previsto no artigo 20 dessa lei, que diz: Art. 20. Praticar, induzir ou incitar a discriminação ou preconceito de raça, cor, etnia, religião ou procedência nacional. Pena: reclusão de um a três anos e multa.

Esse tipo penal apresenta uma semelhança muito grande com o tipo penal da injúria qualificada ${ }^{18}$, especialmente na ação de "praticar", pois o ato de injuriar alguém ofendendo a sua dignidade ou decoro pode se confundir com o ato de praticar discriminação ou preconceito. No entanto, não há de se confundir um crime com outro, pois enquanto a injúria protege a honra subjetiva da vítima, a Lei $7.716 / 89$ protege o sentimento de pertencimento a um grupo étnico, religioso ou a uma procedência comum, bem como o direito da vítima de acessar outros direitos, como ir, vir e permanecer em estabelecimentos públicos e privados, ter um emprego, poder exercer

\footnotetext{
${ }^{15}$ URQUIDI, V. et al. Questão indígena na América Latina: Direito Internacional, novo constitucionalismo e organização dos movimentos indígenas. Cadernos Prolam USP, v. VII, n. I, p. 199-222, 2008.

${ }^{16}$ BRASIL. Lei 6.001 de 19 de dezembro de 1973. Dispõe sobre o Estatuto do Índio. Diário Oficial da União, Brasília, DF, de 21 dez. 1973. Disponível em: <http://www.planalto.gov.br/ccivil_03/Leis/L6001.htm>. Acesso em 28 set. 2015.

17 BRASIL. Lei 6.815 de 19 de agosto de 1980. Define a situação jurídica do estrangeiro no Brasil, cria o Conselho Nacional de Imigração. Diário Oficial da União, Brasília, DF, de 21 ago. 1980. Disponível em: <http://www.planalto.gov.br/ccivil_03/Leis/L6815.htm>. Acesso em 28 set. 2015.

${ }^{18}$ Art. 140 - Injuriar alguém, ofendendo-lhe a dignidade ou o decoro: (...) $3^{\circ}$ Se a injúria consiste na utilização de elementos referentes a raça, cor, etnia, religião, origem ou a condição de pessoa idosa ou portadora de deficiência: Pena - reclusão de um a três anos e multa.
} 
o direito ao orgulho de pertencer a uma raça, a uma cultura, a uma religião ou a um país determinado, protegendo também o direito de todas as pessoas pertencentes à mesma raça, cor, religião, procedência nacional, de exercerem coletivamente esses direitos. A Lei 7.716/89 tem como objetivo a proteção das diferenças, buscando reprimir difusão de ideias preconceituosas e segregacionistas que afrontem a dignidade de todos aqueles pertencentes a uma raça, cor, etnia, religião ou procedência nacional.

Ocorre que apenas a criminalização de condutas preconceituosas e discriminatórias não tem se mostrado suficiente, seja pela omissão dos órgãos estatais que deveriam punir as pessoas que cometem esses crimes, seja pelo fato de a mídia veicular atos e manifestações preconceituosas sem qualquer contextualização ou preocupação de orientar o espectador no sentido de receber as notícias com um posicionamento crítico que não reproduza os atos e manifestações criminosas. Por esse motivo que a educação em direitos humanos pode assumir um papel fundamental na superação do preconceito e na promoção das diferenças possibilitando trocas culturais respeitosas em contextos plurais como o Brasil.

Sobre a educação em direitos humanos, é muito esclarecedor o conceito apresentado por Maria Victoria Benevides:

0 que significa dizer que queremos trabalhar com Educação em Direitos Humanos? A Educação em Direitos Humanos é essencialmente a formação de uma cultura de respeito à dignidade humana através da promoção e da vivência dos valores da liberdade, da justiça, da igualdade, da solidariedade, da cooperação, da tolerância e da paz. Portanto, a formação desta cultura significa criar, influenciar, compartilhar e consolidar mentalidades, costumes, atitudes, hábitos e comportamentos que decorrem, todos, daqueles valores essenciais citados - os quais devem se transformar em práticas. ${ }^{19}$

A Lei de Diretrizes e Bases da Educação Nacional (Lei 9.394/96) dispõe em seu artigo 26, parágrafo $9^{\circ}$ : Conteúdos relativos aos direitos humanos e à prevenção de todas as formas de violência contra a criança e o adolescente serão incluídos, como temas transversais, nos currículos escolares de que trata o caput deste artigo, tendo como diretriz a Lei $n^{0} 8.069$, de 13 de julho de 1990 (Estatuto da Criança e do Adolescente), observada a produção e distribuição de material didático adequado. A previsão expressa da tranversalidade dos conteúdos de direitos humanos na educação é fortalecida pelas Diretrizes Nacionais para a Educação em Direitos Humanos (Resolução/CP $\mathrm{n}$. 01/2012 do Conselho Nacional de Educação) que, além de considerar como princípio o

\footnotetext{
${ }^{19}$ BENEVIDES, M. V. Educação em Direitos Humanos: de que se trata? Convenit Internacional. São Paulo: USP. $\quad$ V. $\quad 6, \quad$ p. $43-50, \quad 2001 . \quad$ Disponível <http://portal.mec.gov.br/seb/arquivos/pdf/Etica/9_benevides.pdf>. Acesso em 27 de julho de 2015.
} 
reconhecimento e valorização das diferenças e das diversidades (artigo $3^{\circ}$ ) e fixar como objetivo central a formação para a vida e para a convivência (artigo $5^{\circ}$ ), prevê a obrigatoriedade da consideração da Educação em Direitos Humanos na construção dos Projetos Político-Pedagógicos (PPP), dos Regimentos Escolares, dos Planos de Desenvolvimento Institucionais (PDI), dos Programas Pedagógicos de Curso (PPC) das Instituições de Educação Superior, dos materiais didáticos e pedagógicos, do modelo de ensino, pesquisa e extensão, de gestão, bem como dos diferentes processos de avaliação (artigo $6^{\circ}$ ).

A educação em direitos humanos assume, assim, um papel de promover práticas e atitudes pautados nos valores da liberdade e da justiça. Em outros termos, além de trabalhar o preconceito presente nos grupos hegemônicos, desenvolve também a consciência da importância da ação e da luta por direitos nos grupos oprimidos. Nesse sentido, no que diz respeito às minorias, uma educação que promova as condições necessárias para que a democracia participativa se enraíze com o protagonismo das minorias exige práticas inclusivas que devem orientar a formação de cidadãos desde o início.

Sobre essa proposta, Pliego y Valero ${ }^{20}$ apresentam distinções muito importantes entre inclusão e integração na educação, e dentre essas distinções selecionamos as seguintes: 1- Na integração os alunos "se preparam" em escolas ou aulas especiais para poder frequentar escolas ou aulas regulares, enquanto a inclusão é incondicional, ou seja, os alunos não precisam "se preparar" para a escola regular; 2- A integração pede concessões aos sistemas, enquanto a inclusão exige rupturas nos sistemas; 3- As mudanças na integração se focam apenas na pessoa diferente ou com a necessidade específica, enquanto a inclusão promove mudanças que beneficiam todas as pessoas; 4- Na integração as pessoas diferentes ou com necessidades específicas se adaptam às necessidades dos modelos que já existem na sociedade, que admitem apenas ajustes, enquanto na inclusão a sociedade se adapta para atender às necessidades das pessoas diferentes ou com necessidades específicas.

A permanência das concepções preconceituosas e discriminatórias em relação às minorias impede o enraizamento de práticas democráticas participativas, pois afetam e tornam impermeável a própria estrutura social. Sem a experiência da alteridade, que nos permite compreender as nossas diferenças a partir das diferenças dos outros, os instrumentos e foros de participação social podem acabar figurando como meras reproduções de uma lógica excludente já presente na estrutura social brasileira.

${ }^{20}$ PLIEGO, N. y VALERO, M. Alumnos inmigrantes en España: una realidad creciente. In. Hekademos Revista Educativa Digital. v. IV, n. 8. Sevilla: AFOE Formación, 2011. p. 77-90. 
Uma educação que promova a consciência da alteridade, precisa avançar no sentido de considerar no caso das migrações, por exemplo, que se trata de um processo que marcou toda a história da humanidade e hoje esses processos se intensificaram em razão da amplitude e rapidez dos meios de transporte, mas também do imediatismo e da intensidade da circulação de informações. Além disso, precisa considerar que a dinâmica do sistema capitalista, sua produção de desigualdades (portanto, produção da pobreza de muitos em nome da riqueza de poucos) e a necessidade de mãode-obra barata e precária para manter a competitividade das empresas capitalistas, fazem girar o motor das migrações.

Do mesmo modo, a compreensão de que cada grupo social e cultural possui uma visão de mundo própria e que não existe apenas um modo de produção é fundamental para a superação das propostas assimilacionistas e integracionistas em relação aos povos indígenas, aos quilombolas e outras minorias. No caso do sistema capitalista em que se inserem e que determina grandemente as migrações contemporâneas, é importante trazer a atenção ao fato de que o próprio sistema promove o deslocamento e o consequente "encontro" entre culturas diferentes; o que intensifica a problemática da hierarquização entre culturas e da assimilação à cultura dominante. Não foi por menos que no artigo 380 do Anteprojeto Constitucional apresentado pela Comissão Afonso Arinos constava: O Governo Federal, reconhecendo as populações indígenas como parte integrante da comunidade nacional, proporá legislação específica com vista à proteção destas populações e de seus direitos originários.

Reconhecer expressamente que as populações indígenas são partes integrantes da comunidade nacional era uma forma de superar no texto constitucional a proposta de "integrar o índio à comunhão nacional” que existe no artigo 50 do Estatuto do Índio (Lei 6.001/1973): A educação do índio será orientada para a integração na comunhão nacional mediante processo de gradativa compreensão dos problemas gerais e valores da sociedade nacional, bem como do aproveitamento das suas aptidões individuais. Apesar de o texto constante no Anteprojeto não ter sido incorporado à Constituição, a superação da proposta assimilacionista do Estatuto do Índio se deu com o artigo 231, que reconheceu aos índios os seus costumes, crenças e tradições.

Para os imigrantes, tal proteção não existe. Na lógica do Estado-nação e do sistema capitalista, eles são apenas mão-de-obra. A atual reivindicação de seus direitos humanos traz à cena a constatação, não inédita, de que não é possível separar as condições de trabalhadores e de seres humanos com identidades e culturas diversas. Há no Brasil o mito do país formado por imigrantes, no entanto, hoje já aparecem manifestações de rejeição e condenação aos imigrantes e suas culturas diferentes, sobretudo quando elas extrapolam a culinária que é oferecida aos brasileiros e 
reivindicam a consideração de suas culturas nos serviços públicos de saúde e educação, por exemplo. Em um processo de construção da interculturalidade o Brasil deve mudar e cada uma das culturas certamente se modificará, como antes já ocorreu também; ainda que se espere que agora o processo possa ser mais equânime e respeitoso.

Nesse sentido, é com a superação do racismo com a coibição de atos preconceituosos e com a promoção de educação inclusiva que a experiência da alteridade poderá criar condições para o enraizamento de práticas democráticas participativas como uma forma de garantia e promoção de direitos humanos de minorias em contextos plurais. A alteridade, nessa linha, diz respeito às experiências nas quais nos reconhecemos como diferentes a partir das diferenças dos outros. Ações que busquem implementar a discussão sobre diversidade e minorias no âmbito da educação devem ser fortalecidas como condição inicial para o enraizamento de práticas democráticas participativas que possam se pautar no respeito, na convivência e no compartilhamento não violento de espaços geográficos e políticos comuns.

\section{DEMOCRACIA E PARTICIPAÇÃO SOCIAL}

Sabemos que a democracia direta, entendida como algo semelhante ao que se passou em outros tempos em que os cidadãos se encontravam e manifestavam suas opiniões nas praças, é algo muito distante da nossa realidade. Mesmo quando pensamos em conselhos populares, como os conselhos de saúde, os cidadãos que representam a sociedade civil exercem, ainda assim, um papel de representação, daí que a melhor proposta pode ser a compreensão de uma democracia participativa que, concretamente, avança em relação à democracia simplesmente representativa, que tem dado mostras de insuficiência no Brasil. Nessa linha, o modelo de democracia que melhor dialoga com os direitos humanos, a interculturalidade e a participação das minorias são a democracia participativa, fortalecida por instrumentos e foros abertos às minorias, aos coletivos e grupos que não precisam se despir de suas diferenças para participar nas tomadas de decisão sobre assuntos públicos de onde vivem. ${ }^{21}$

\footnotetext{
${ }^{21}$ Para aprofundar a reflexão, conferir o texto Três modelos normativos de democracia, em que Jürgen Habermas trabalha a concepção liberal, a concepção republicana e sugere uma concepção de democracia deliberativa, que leva em conta a pluralidade de formas de comunicação nas quais a vontade comum pode se formar (...) não somente pela via de uma autocompreensão ética, mas também mediante o equilíbrio de interesses e compromissos, mediante a escolha racional de meios com respeito a um fim, mediante justificações morais e exames de coerência jurídicos.( HABERMAS, J. Três modelos normativos de democracia. Lua Nova [online]. n. 36, pp. 39-53, 1995)
} 
Recentemente foi editado o Decreto 8.243, de 23 de maio de 2014, que instituiu a Política Nacional de Participação Social - PNPS, com o objetivo de fortalecer e articular os mecanismos e as instâncias democráticas de diálogo e a atuação conjunta entre a Administração Pública Federal e a sociedade civil. Esse Decreto teve seus efeitos sustados pelo Congresso Nacional num momento político conservador e de esforços empreendidos para a concretização de retrocessos que se instalou no Brasil, no entanto a compreensão de alguns avanços desse Decreto é muito didática para esclarecer o objetivo deste artigo.

Esse Decreto avançou num ponto muito importante, qual seja no ponto em que reconhecia como "sociedade civil" não apenas o cidadão e os movimentos sociais institucionalizados, mas também os coletivos e os movimentos sociais não institucionalizados (artigo $2^{\circ}$, inciso I), além de ter consagrado como diretriz da Política o direito à informação, à transparência e ao controle social nas ações públicas, com uso de linguagem simples e objetiva, consideradas as características e o idioma da população a que se dirige (artigo $3^{\circ}$, inciso IV), aspecto fundamental para a participação efetiva de indígenas e imigrantes, por exemplo.

A ampliação dos atores reconhecidos e a institucionalização legal de um conjunto amplo de vias participativas ${ }^{22}$ representou um avanço significativo para as lutas populares e para o fortalecimento da cidadania exercida "de baixo para cima". Ainda que esse Decreto tenha tido seus efeitos sustados, a existência de instrumentos e foros participativos, como a consulta prévia aos povos indígenas e a inclusão de imigrantes nos Conselhos Participativos da cidade de São Paulo demonstra que essas práticas estão em curso no país e merecem toda atenção para o seu fortalecimento.

Outra questão importante é entender o que queremos dizer quando abordamos o tema da participação social. A participação social, entendida enquanto participação nos assuntos públicos é um direito consagrado em vários instrumentos legais de direitos humanos, podendo ser citados vários documentos de relevância nacional e internacional a esse respeito: o artigo 25 do Pacto de Direitos Civis e Políticos de $1966^{23}$ (Decreto n. 592 de 06 de julho de 1992); os artigos 6, 1, b, e 7, 1 e 2 da

\footnotetext{
${ }^{22} 0$ artigo $6^{\circ}$ do Decreto reconhece como instâncias e mecanismos de participação social: I - conselho de políticas públicas; II - comissão de políticas públicas; III - conferência nacional; IV - ouvidoria pública federal; V - mesa de diálogo; VI - fórum interconselhos; VII - audiência pública; VIII - consulta pública; e IX - ambiente virtual de participação social.

${ }^{23}$ Artigo 25 - Todo cidadão terá o direito e a possibilidade, sem qualquer das formas de discriminação mencionadas no artigo $2^{\circ}$ e sem restrições infundadas: a) de participar da condução dos assuntos
} 
Convenção 169 da Organização Internacional do Trabalho ${ }^{24}$ (Decreto n. 5.051 de 19 de abril de 2004); o artigo 23, 1, a, da Convenção Americana sobre Direitos Humanos ${ }^{25}$ (Pacto de São José da Costa Rica, internalizado no Brasil pelo Decreto Legislativo 27/1992).

Normalmente, a participação é pensada em termos de exercício da cidadania e a noção tradicional de cidadania exclui alguns grupos do direito a participar da condução dos assuntos públicos de onde se vive. A concepção tradicional de cidadania, conectada diretamente com o exercício de direitos políticos em sentido estrito - direito de votar e ser votado - em geral exclui os imigrantes, a quem não se reconhece a titularidade destes direitos. Viver em uma sociedade em relação à qual não podem opinar os exclui e viola seus direitos. Nessa linha, nos parece muito preciso o conceito de "política" apresentado numa obra de autoria de Dalmo de Abreu Dallari e cujo título é $O$ que é participação política. Nessa obra, Dallari afirma que "política" se refere à vida na polis, ou seja, à vida em comum, às regras de organização dessa vida, aos objetivos da comunidade e às

públicos, diretamente ou por meio de representantes livremente escolhidos; b) de votar e de ser eleito em eleições periódicas, autênticas, realizadas por sufrágio universal e igualitário e por voto secreto, que garantam a manifestação da vontade dos eleitores; c) de ter acesso em condições gerais de igualdade, às funções públicas de seu país.

24 Artigo $6^{\circ}-1$. Ao aplicar as disposições da presente Convenção, os governos deverão: a) consultar os povos interessados, mediante procedimentos apropriados e, particularmente, através de suas instituições representativas, cada vez que sejam previstas medidas legislativas ou administrativas suscetíveis de afetálos diretamente; b) estabelecer os meios através dos quais os povos interessados possam participar livremente, pelo menos na mesma medida que outros setores da população e em todos os níveis, na adoção de decisões em instituições efetivas ou organismos administrativos e de outra natureza responsáveis pelas políticas e programas que lhes sejam concernentes; c) estabelecer os meios para o pleno desenvolvimento das instituições e iniciativas dos povos e, nos casos apropriados, fornecer os recursos necessários para esse fim. 2 . As consultas realizadas na aplicação desta Convenção deverão ser efetuadas com boa fé e de maneira apropriada às circunstâncias, com o objetivo de se chegar a um acordo e conseguir o consentimento acerca das medidas propostas.

Artigo $7^{\circ}-1$. Os povos interessados deverão ter o direito de escolher suas próprias prioridades no que diz respeito ao processo de desenvolvimento, na medida em que ele afete as suas vidas, crenças, instituições e bem-estar espiritual, bem como as terras que ocupam ou utilizam de alguma forma, e de controlar, na medida do possível, o seu próprio desenvolvimento econômico, social e cultural. Além disso, esses povos deverão participar da formulação, aplicação e avaliação dos planos e programas de desenvolvimento nacional e regional suscetíveis de afetá-los diretamente. 2. A melhoria das condições de vida e de trabalho e do nível de saúde e educação dos povos interessados, com a sua participação e cooperação, deverá ser prioritária nos planos de desenvolvimento econômico global das regiões onde eles moram. Os projetos especiais de desenvolvimento para essas regiões também deverão ser elaborados de forma a promoverem essa melhoria.

${ }^{25}$ Artigo 23 - Direitos políticos - 1. Todos os cidadãos devem gozar dos seguintes direitos e oportunidades: a) de participar da condução dos assuntos públicos, diretamente ou por meio de representantes livremente eleitos; 
decisões sobre todos esses pontos e, nessa linha, conceitua: "Política é a conjugação das ações de indivíduos e grupos humanos, dirigindo-as a um fim comum ${ }^{26}$."

A referência à vida na polis se justifica na origem grega do termo, mas o fundamento da polis era exatamente a referência ao lugar onde as pessoas viviam juntas. Assim sendo, o agir político é exatamente o compromisso com a definição das melhores regras para o convívio em comum. Nessa linha, Dallari ainda registra que a participação política de todos é um critério de justiça, pois o ser humano não é apenas um animal que vive, mas um animal que convive, e essa convivência pode sempre criar possibilidades de conflitos de modo que se faz necessário encontrar uma forma de organização da convivência de modo a tornar menos grave esses conflitos. Sobre essa questão, Dallari ainda afirma: “Ao mesmo tempo, é preciso lembrar que todos os seres humanos são essencialmente iguais por natureza. Em consequência, não será justa uma sociedade em que apenas uma parte possa decidir sobre a organização social e tenha respeitada a sua individualidade ${ }^{27}$."

Como afirmamos, no Brasil existem instrumentos e foros de participação social muito importantes que, em razão de retrocessos históricos que estamos presenciando em relação à participação, merecem ser estudados e fortalecidos. No Brasil existe a previsão de consulta prévia para os casos de aproveitamento dos recursos hídricos, incluídos os potenciais energéticos, a pesquisa e a lavra das riquezas minerais em terras indígenas no artigo 231, parágrafo $3^{\circ 28}$, da Constituição e também para os casos de acesso a conhecimento tradicional, situação recente prevista na Lei 13.123, de 20 de maio de $2015^{29}$.

Além dessas previsões específicas, a consulta prévia também é assegurada no artigo $6^{\circ}$ da Convenção 169 da Organização Internacional do Trabalho (Decreto n. 5.051 de 19 de abril de 2004) todas as vezes que forem previstas medidas legislativas ou administrativas suscetíveis de afetar diretamente os povos indígenas ou tribais. Algumas comunidades tradicionais ${ }^{30}$ já formularam seus

\footnotetext{
${ }^{26}$ DALLARI, D. A. O que é participação política. São Paulo: Abril Cultural: Brasiliense, 1984. p. 10.

${ }^{27}$ Id. p. 16.

${ }^{28} \mathrm{Art}$. 231 , $3^{\circ} 0$ aproveitamento dos recursos hídricos, incluídos os potenciais energéticos, a pesquisa e a lavra das riquezas minerais em terras indígenas só podem ser efetivados com autorização do Congresso Nacional, ouvidas as comunidades afetadas, ficando-lhes assegurada participação nos resultados da lavra, na forma da lei.

${ }^{29} \mathrm{O}$ artigo $9^{\circ}$ dessa lei diz que o acesso ao conhecimento tradicional associado de origem identificável está condicionado à obtenção do consentimento prévio informado.

${ }^{30} \mathrm{~A}$ definição de povos tradicionais é feita pelo Decreto 6.040 de 2007 que, no seu artigo $3^{\circ}$, reconhece como "povos ou comunidades tradicionais" aqueles grupos culturalmente diferenciados e que se reconhecem como tais, que possuem formas próprias de organização social, que ocupam e usam
} 
próprios protocolos de consulta, como os Wajãpi, os Munduruku e os beiradeiros do Projeto Agroextrativista Montanha e Mangabal ${ }^{31}$.

No que se refere aos imigrantes, a experiência dos conselhos participativos na a Prefeitura de São Paulo tem garantido a sua participação nesses conselhos territoriais. Os Conselhos Participativos foram criados pela Lei 15.764 de 27 de maio de 2013 (artigos 34 e 35) e regulamentados pelo Decreto 56.208 de 30 de junho de 2015. 0 artigo $2^{\circ}$, parágrafo $1^{\circ}$ do referido Decreto esclarece as suas principais funções:

$\S 1^{\circ} 0$ Conselho Participativo Municipal tem caráter eminentemente público e é organismo autônomo da sociedade civil, reconhecido pelo Poder Público Municipal como instância de representação da população de cada região da Cidade para exercer o direito dos cidadãos ao controle social, por meio da fiscalização de ações e gastos públicos, bem como da apresentação de demandas, necessidades e prioridades na área de sua abrangência.

Em 2013 foram criadas cadeiras para imigrantes nas Subprefeituras de maior concentração de imigrantes na cidade. $\mathrm{Na}$ ocasião, 19 imigrantes de 12 nacionalidades diferentes foram eleitos. $\mathrm{O}$ dia da eleição também revestiu-se de grande simbolismo, no que se refere à participação social das comunidades de imigrantes, ainda hoje, grandemente excluídas. Em 2015, as cadeiras para imigrantes foram ampliadas para as 32 Subprefeituras da cidade e o processo eleitoral geral e o dos imigrantes também está implementando a Lei 15.946 de 23 de dezembro de 2013, que determina a composição mínima de $50 \%$ de mulheres na representação dos conselhos de controle social da cidade de São Paulo.

Em São Paulo a presença de indígenas é significante em razão das perseguições sofridas durante a ditadura civil-militar, sendo também significativa a presença de imigrantes, situação que apenas recentemente se tornou realidade para muitos municípios brasileiros. A imigração também entrou na agenda nacional, mas o olhar sobre o tema e para os próprios imigrantes por parte de instituições públicas e privadas ainda permanece fortemente pautado pela caridade (situação também identificada em relação aos indígenas). Essa abordagem contrapõe-se à abordagem da participação social, da reivindicação de direitos, do empoderamento destes sujeitos e serve somente àqueles que desejam manter os imigrantes e indígenas sob controle ou sob seu controle. A

territórios e recursos naturais como condição para sua reprodução cultural, social, religiosa, ancestral e econômica, utilizando conhecimentos, inovações e práticas gerados e transmitidos pela tradição.

31 Os protocolos podem ser encontrados no site <http://cpisp3.wix.com/proindio-saopaulo> Acesso em 29 de setembro de 2009. 
experiência da participação dos indígenas nas experiências de consulta prévia e dos imigrantes nos Conselhos Participativos, apesar dos limites do próprio formato dos Conselhos - que são transitórios, em vista de sua futura substituição pelos Conselhos de Representantes ${ }^{32}$ - tem se mostrado efetiva no sentido de empoderar e dar voz a esses grupos. Pode ser um prática singela, mas revela uma concepção sobre o exercício da cidadania não apenas dos indígenas, mas também dos imigrantes extremamente relevante.

Tanto a consulta prévia aos povos tradicionais, como a possibilidade de imigrantes integrarem conselhos participativos em São Paulo e outras práticas participativas de minorias fortalecem práticas importantes para o enraizamento de processos de democracia participativa no Brasil e, por isso mesmo, precisam ser conhecidas, promovidas e fortalecidas.

\section{CONCLUSÃO}

Neste artigo nos propusemos a pensar a participação social das minorias e registrar avanços importantes no fortalecimento de instrumentos de democracia participativa, como a consulta prévia aos povos indígenas e os conselhos participativos para os imigrantes. A democracia brasileira é uma experiência ainda recente e ultimamente temos presenciado alguns retrocessos. Exatamente por isso o registro de avanços importantes no que diz respeito à ampliação das vias de participação popular na formulação de leis e de políticas públicas que afetam as minorias é uma forma de promover e seguir avançando no enraizamento social da democracia no Brasil.

Seja no campo da educação em direitos humanos com a formulação de material didático objetivando práticas de educação inclusiva, seja no campo da criminalização de ações preconceituosas e discriminatórias contra minorias étnicas, religiosas, imigrantes e outros grupos vulneráveis econômica, política e socialmente, podemos identificar medidas importantes para a criação de condições importantes para o exercício do direito à participação política por indivíduos e grupos minoritários no Brasil. A garantia de consulta prévia, de acesso aos conselhos participativos, não pode prescindir de ações integradas no sentido de formar esses indivíduos e grupos para o exercício da cidadania e, mais do que isso, preparar toda a sociedade civil e os agentes públicos para conviver de forma respeitosa e não-violenta com as minorias.

${ }^{32}$ Artigos 54 e 55 da Lei Orgânica do Município de São Paulo. 
Uma democracia participativa que promova direitos humanos não pode olvidar a necessidade de garantir aos grupos minoritários a participação efetiva nas tomadas de decisão sobre os assuntos públicos do país e, como registramos, apesar do momento conservador que temos vivido no Brasil existem leis e práticas democráticas em curso que, sim, ainda precisam ser aprimoradas, mas que também merecem ser colocadas em evidência de modo a evitar mais retrocessos.

\section{REFERÊNCIAS}

ANDRADE, J. C. V. Os direitos fundamentais na Constituição de 1976. 2. ed. Coimbra: Almedina, 2001.

BAUMAN, Z. Em busca da política. Tradução de Marcos Penchel. Rio de Janeiro: Jorge Zahar Ed, 2000.

BENEVIDES, M. V. Educação em Direitos Humanos: de que se trata? Convenit Internacional. São Paulo: USP. v. 6, p. 43-50, 2001. Disponível em:

<http://portal.mec.gov.br/seb/arquivos/pdf/Etica/9_benevides.pdf>. Acesso em 27 de julho de 2015.

BUNCHAFT, M. E. O patriotismo constitucional na perspectiva de Jürgen Habermas: a reconstrução da ideia de nação na filosofia política contemporânea. Rio de Janeiro: Lumen Júris, 2010, p. 42.

Algumas críticas à ideia de patriotismo constitucional. Pensar, v. 16, n. 1, p.

224-245, Fortaleza, jan./jun. 2011.

CANOTILHO, J.J. Gomes. Direito Constitucional. 5. ed. Coimbra: Almedina, 1991.

DAGNINO, E. Os movimentos sociais e a emergência de uma nova noção de cidadania. In. DAGNICNO, E (org.), Anos 90 - Política e sociedade no Brasil, Ed. Brasiliense, 1994. p. 103-115.

DALLARI, D. A. O que é participação política. São Paulo: Abril Cultural: Brasiliense, 1984.

DUSSEL, E. Transmodernidad e interculturalidad -Interpretación desde la Filosofía de la Liberación. In: FORNET-BETANCOURT, R. Crítica Intercultural de la Filosofía Latinoamericana Actual. Madrid, pp. 123-160, 2004.

FLORES, Joaquin Herrera. Direitos Humanos, Interculturalidade e Racionalidade de Resistência. Sequência (UFSC), vol. 23, n. 44, p. 09 a 29, 2002. ISSNe 2177-7055.

HABERMAS, J. Três modelos normativos de democracia. Lua Nova [online]. n. 36, pp. 39-53, 1995.

PLIEGO, N. y VALERO, M. Alumnos inmigrantes en España: una realidad creciente. In. Hekademos Revista Educativa Digital. v. IV, n. 8. Sevilla: AFOE Formación, 2011. p. 77-90.

SANTOS, B. S. A gramática do tempo: para uma nova cultura política. 3 ed. São Paulo: Cortez, 2010. 
SCHWARCZ, Lilia Moritz. O espetáculo das raças: cientistas, instituições e questão racial no Brasil, 1870 - 1930. São Paulo: Companhia das Letras, 1993.

SEYFERTH, Giralda. As identidades dos imigrantes e o melting pot nacional. Horizontes Antropológicos, Porto Alegre, ano 6, n. 14, 2000.

SOUSA, R. S. Direitos humanos através da história recente em uma perspectiva antropológica. In: NOVAES, R. R. e KANT DE LIMA, R. (orgs.). Antropologia e direitos humanos. Niterói: EdUFF, 2001. p. 47-79.

URQUIDI, V. et al. Questão indígena na América Latina: Direito Internacional, novo constitucionalismo e organização dos movimentos indígenas. Cadernos Prolam USP, v. VII, n. I, p. 199-222, 2008.

COMISSÃO NACIONAL DA VERDADE. Relatório Final. Texto 5 - Violações de direitos humanos dos povos indígenas. p. 203-264. Brasília, 2014.

BRASIL. Lei 6.001 de 19 de dezembro de 1973. Dispõe sobre o Estatuto do Índio. Diário Oficial da União, Brasília, DF, de 21 dez. 1973. Disponível em:

<http://www.planalto.gov.br/ccivil_03/Leis/L6001.htm>. Acesso em 28 set. 2015.

BRASIL. Lei 6.815 de 19 de agosto de 1980. Define a situação jurídica do estrangeiro no Brasil, cria o Conselho Nacional de Imigração. Diário Oficial da União, Brasília, DF, de 21 ago. 1980. Disponível em: <http://www.planalto.gov.br/ccivil_03/Leis/L6815.htm>. Acesso em 28 set. 2015.

BRASIL. Constituição Federal. Brasília: Senado Federal, 1988. Disponível em: <http://www.planalto.gov.br/ccivil_03/Constituicao/Constituicao.htm>. Acesso em 28 set. 2015.

BRASIL. Lei 7.716 de 05 de janeiro de 1989. Define os crimes resultantes de preconceito de raça ou de cor. Diário Oficial da União, Brasília, DF, 06 jan. 1989. Disponível em:

<http://www.planalto.gov.br/ccivil_03/LEIS/L7716.htm>. Acesso em 28 set. 2015.

BRASIL. Decreto n. 592 de 06 de julho de 1992. Atos Internacionais. Pacto Internacional sobre Direitos Civis e Políticos. Promulgação. Diário Oficial da União, Brasília, DF, de 07 jul. 1992. Disponível em: <http://www.planalto.gov.br/ccivil_03/decreto/1990-1994/D0592.htm>. Acesso em 28 set. 2015.

BRASIL. Decreto n. 678 de 06 de novembro de 1992. Promulga a Convenção Americana sobre Direitos Humanos (Pacto de São José da Costa Rica), de 22 de novembro de 1969. Diário Oficial da União, Brasília, DF, de 09 nov. 1992. Disponível em: < http://www.planalto.gov.br/ccivil_03/decreto/D0678.htm>. Acesso em 28 set. 2015.

BRASIL. Lei 9.394 de 20 de dezembro de 196. Estabelece as diretrizes e bases da educação nacional. Diário Oficial da União, Brasília, DF, de 20 dez. 1996. Disponível em:

<http://www.planalto.gov.br/ccivil_03/Leis/L9394.htm>. Acesso em 28 set. 2015.

BRASIL. Decreto n. 5.051 de 19 de abril de 2004. Promulga a Convenção n 169 da Organização Internacional do Trabalho - OIT sobre Povos Indígenas e Tribais. Diário Oficial da União, Brasília, DF, de 20 abr. 2004. Disponível em: <http://www.planalto.gov.br/ccivil_03/_ato2004-

2006/2004/decreto/d5051.htm>. Acesso em 28 set. 2015.

BRASIL. Decreto n. 6.040 de 07 de fevereiro de 2007. Institui a Política Nacional de Desenvolvimento Sustentável dos Povos e Comunidades Tradicionais. Diário Oficial da União, Brasília, DF, de 08 fev. 
2007. Disponível em: <http://www.planalto.gov.br/ccivil_03/_ato2007-

2010/2007/decreto/d6040.htm>. Acesso em 28 set. 2015.

BRASIL. Conselho Nacional de Educação. RESOLUÇÃO n 1 , de30 de maio de 2012. Disponível em: <http://mobile.cnte.org.br:8080/legislacao-externo/rest/lei/93/pdf>. Acesso em 14 de out. de 2015.

BRASIL. Decreto n. 8.243 de 23 de maio de 2014. Institui a Política Nacional de Participação Social PNPS e o Sistema Nacional de Participação Social - SNPS, e dá outras providências. Diário Oficial da União, Brasília, DF, de 26 mai. 2014. Disponível em:

<http://www.planalto.gov.br/ccivil_03/_Ato2011-2014/2014/Decreto/D8243.htm>. Acesso em 28 set. 2015.

BRASIL. Lei 13.123 de 20 de maio de 2015. Regulamenta o inciso II do $\S 1^{\circ}$ e o $\S 4^{\circ}$ do art. 225 da Constituição Federal, o Artigo 1, a alínea $j$ do Artigo 8, a alínea c do Artigo 10, o Artigo 15 e os $\S \S 3^{\circ}$ e $4^{\circ}$ do Artigo 16 da Convenção sobre Diversidade Biológica, promulgada pelo Decreto $\mathrm{n}^{\circ} 2.519$, de 16 de março de 1998; dispõe sobre o acesso ao patrimônio genético, sobre a proteção e o acesso ao conhecimento tradicional associado e sobre a repartição de benefícios para conservação e uso sustentável da biodiversidade; revoga a Medida Provisória n 2.186-16, de 23 de agosto de 2001; e dá outras providências. Diário Oficial da União, Brasília, DF, de 14 mai. 2015. Disponível em: < http://www.planalto.gov.br/ccivil_03/_Ato2015-2018/2015/Lei/L13123.htm>. Acesso em 28 set. 2015.

SÃO PAULO. Lei Orgânica de São Paulo. São Paulo, 4 de abril de 1990. Disponível em <http://www.prefeitura.sp.gov.br/cidade/secretarias/upload/educacao/cme/LOM.pdf>. Acesso em 30 set. 2015.

SÃO PAULO. Lei 15.764 de 27 de maio de 2013. Dispõe sobre a criação e alteração da estrutura organizacional das Secretarias Municipais que especifica, cria a Subprefeitura de Sapopemba e institui a Gratificação pela Prestação de Serviços de Controladoria. Publicada na Secretaria do Governo Municipal, em 27 de maio de 2013.

SÃO PAULO. Decreto 56.208 de 30 de junho de 2015. Confere nova regulamentação ao Conselho Participativo Municipal em cada Subprefeitura a que se referem os artigos 34 e 35 da Lei n 15.764 , de 27 de maio de 2013. Diário Oficial da Cidade de São Paulo, 01/07/2015.

<https: / /mobilizacaonacionalindigena.wordpress.com/2014/02/12/deputado-ruralista-diz-quequilombolas-indios-e-homossexuais-sao-tudo-o-que-nao-presta-e-defende-que-fazendeiros-usemarmas/>. Acesso em 02 de agosto de 2015.

<http://justificando.com/2015/06/30/imigracao-preconceito-e-discriminacao-=-crime/>, acesso em 26 de setembro de 2015.

<http://cpisp3.wix.com/proindio-saopaulo> Acesso em 29 de setembro de 2009.

Recebido em: 01.10.2015 / Revisado em 13.10.2015 Aprovado em: 15.10.2015 